\title{
Students' awareness of malaria at the beginning of national malaria elimination programme in China
}

\author{
Jian-hai Yin ${ }^{1,2,3}$, Ru-bo Wang ${ }^{1,2,3}$, Zhi-gui Xia ${ }^{1,2,3^{*}}$, Shui-sen Zhou ${ }^{1,2,3}$, Xiao-nong Zhou ${ }^{1,2,3}$, Qing-feng Zhang ${ }^{1,2,3}$ \\ and Xin-yu Feng ${ }^{1,2,3}$
}

\begin{abstract}
Background: In the battle against malaria in China, the rate of elementary and high school students' awareness on malaria knowledge is an important index for malaria elimination, but only rare data is available. This study aimed to investigate the level of malaria awareness in students at elementary and high schools in malaria endemic areas of China, and to provide the baseline information for the malaria elimination.

Methods: This cross-sectional survey was conducted in 20 different malaria-endemic provinces in the first year of China's National Malaria Elimination Programme (NMEP). A structured questionnaire was administrated to students at elementary and high schools enrolled. A total of 44,519 questionnaires were effective while 1,220 were excluded because of incomplete survey responses.

Results: More than $60 \%$ of students were aware of malaria, but only 9,013 of them answered correctly to all five questions, and there were still 1,862 students unaware of malaria. There were significant differences of the awareness of malaria among different age groups, between male and female, between two different education levels.

Discussion: The study reveals that students at elementary and high school levels did not have adequate knowledge of malaria about biology, pathogenicity, transmitting vectors and preventive methods and so on at the beginning of NMEP in China. Further emphasis should be paid on health education campaigns in China to increase students' public awareness of malaria about vector control, treatment, prevention.
\end{abstract}

Keywords: Awareness, Malaria, Students, China

\section{Background}

Malaria, one of the category B notifiables diseases in China, was reduced dramatically as a result of unprecedented governmental efforts. In order to better protect and promote public health, to achieve the health-related Millennium Development Goals, the Chinese government launched a national campaign with the goal of eliminating the disease nationwide by 2020. An action plan of malaria elimination as a guidance document was issued in 2010 [1]. In the battle against malaria, in

\footnotetext{
* Correspondence: Zhi-gui Xia nipdxzhg@163.com

'National Institute of Parasitic Diseases, Chinese Center for Disease Control

and Prevention, Shanghai 200025, People's Republic of China

${ }^{2}$ WHO Collaborating Centre for Malaria, Schistosomiasis and Filariasis,

Shanghai 200025, People's Republic of China

Full list of author information is available at the end of the article
}

addition to case finding, treatment, surveillance and vector control, health education was an indispensable part [2], and the rate of elementary and high school students' awareness on malaria knowledge will be assessed according to this action plan. It targeted that $75 \%$ of students in these two-level schools should have knowledge of malaria prevention and treatment by 2012, and $85 \%$ should reach that by 2015 . Finally by 2020 , the awareness of malaria should be improved further and people should participate in malaria prevention, control and elimination more proactively [1].

However, malaria awareness campaigns are often restricted to providing information at health posts, and not readily available to students at primary and high school levels. These campaigns are also usually aimed at 
informing people about vector control activities, and to motivate people to make use of the provided control measures such as spraying insecticide indoors, with little focus on actions that individual community members can take to not only help themselves, but to help the overall effectiveness of the local malaria control interventions [3]. It is noted that students can be important agents for change. Health education through schools can help promote a community-wide understanding of malaria and the need for control and can create a demand for health services to provide universal access to affordable and appropriate treatment $[4,5]$.

In this study, a cross-sectional investigation into students' perceptions of malaria-related basic knowledge at the primary and high school levels was carried out nationwide at the beginning of the NMEP, to understand the current status of students' awareness of malaria and provide the most recent baseline data for malaria prevention and control, so that corresponding measures can be carried out, and effectiveness evaluation can be done when malaria elimination is achieved.

\section{Methods}

\section{Study populations and sampling}

This cross-sectional study was conducted between September and December 2010. The study population was obtained from students at elementary and high schools from malaria-endemic counties in 20 provinces in China using multistage cluster sampling. Firstly, 16 Type I malaria-endemic counties (local infections detected in three consecutive years and the annual incidences no less than $1 / 10,000$ respectively) [1] and 78 Type II counties (local infections detected in three consecutive years and the annual incidences lower than $1 / 10,000$ at least in one year) [1] in 20 provinces were randomly selected. Secondly, three towns representing high, middle and low malaria epidemics respectively in recent years were selected in every county. Thirdly, one elementary school and one high school were selected in each town. Finally, no fewer than 60 students in every school were surveyed.

\section{Questionnaire design}

Demographic information comprising of code, province, city, county, school, class grade, and the individual information of name, gender and age were included in the questionnaire. For ease of understanding and operation, five simple but important malaria knowledge choice questions related to malaria vectors, main symptoms, fatal malaria species, what should do when get malaria, and malaria prevention approaches, were set to assess the perception of malaria. Each question was awarded one mark for correct answer, while each incorrect answer was given zero marks. The total marks of five questions were evaluated as follows: scores of five were considered "excellent", while scores of three to four, one to two and zero were considered "good", "poor" and "very poor", respectively. And the ranks of "excellent" and "good" were considered as "aware", otherwise were "not aware".

\section{Data collection and quality control}

Before the survey, investigators from provincial Center for Disease Control and Prevention (CDC)were uniformly trained by national professionals, then investigators at county level were trained by the provincials. The questionnaire was administrated to every student for fulfilment with support from professionals and schoolteachers during the first implementation year of the NMEP. All data were rechecked step-by-step and typed into a designed database.

\section{Data analysis}

Using Microsoft Excel 2010 software, the constituent ratios of different aspects were calculated. Differences in distribution were evaluated using the chi-square $\left(x^{2}\right)$ test by SPSS version 16.0 and $P<0.05$ was considered statistically significant.

\section{Ethical considerations}

The study was reviewed and approved by the Ethical Committee of NIPD, China CDC. All participants included were provided verbal informed consent before admission into the study with the help of schoolteachers.

\section{Results}

\section{Demographic characteristics of enrolled students}

A total of 44,519 questionnaires were effective while 1,220 were excluded because of incomplete survey responses in this cross-sectional study. The majority (76.94\%) of students were aged from ten to 14 years old. The ratio of male to female was close to 1 . Students from elementary schools (52.22\%) were slightly more than students from high schools (47.78\%). The details from these questionnaires are presented in Table 1.

\section{Knowledge of malaria}

All students' understanding of malaria knowledge was not the same. Among 44,519 effective questionnaires, the percentage of correct responses to three questions about malaria vectors, symptoms, fatal species was between 56 and $60 \%$, and $88.09 \%$ of students had knowledge of approaches to treat malaria. However, only $35.07 \%$ of all students knew the preventive measures against malaria. The details are presented in Table 2.

\section{Awareness of malaria}

Among the effective questionnaires, only 9,013 students responded correctly to all five questions, and 1,862 
Table 1 Demographic characteristics of students of effective questionnaires $(n=44,519$ )

\begin{tabular}{lll}
\hline Characteristic & $\mathbf{n}$ & $\%$ \\
\hline Age group, years & & \\
$6-9$ & 2,446 & 5.49 \\
$10-14$ & 34,254 & 76.94 \\
$\geq 15$ & 7,819 & 17.56 \\
Sex & & \\
Male & 22,649 & 50.87 \\
Female & 21,870 & 49.13 \\
Education & & \\
Elementary school & 23,249 & 52.22 \\
High school & 21,270 & 47.78 \\
\hline
\end{tabular}

students were unaware of malaria. Only $60.46 \%$ of students were aware of malaria; most were ranked as "good" grade. Furthermore, there were significant differences of awareness of malaria among three age groups $(P=0.027)$, the percentages were $58.95 \%$ (age six to nine), $60.29 \%$ (age ten to 14 ) and $61.63 \%$ (age $\geq 15$ ), respectively. Awareness of malaria was better in females than males $(P=0.022)$. In addition, awareness of malaria in high school students was better than in elementary school students $(P<0.001)$. The details are presented in Table 3 .

\section{Discussion}

In China, malaria has a recorded history of more than 4,000 years and was identified as one of the top five

Table 2 Distribution of knowledge of malaria related in students at elementary and high school levels in China ( $n=44,519$ )

\begin{tabular}{lcc}
\hline \multicolumn{1}{l}{ Items } & $\mathbf{n}$ & $\%$ \\
\hline $\begin{array}{l}\text { Which transmit malaria? } \\
\text { Correct }\end{array}$ & 26,325 & 59.13 \\
Incorrect & 18,194 & 40.87 \\
Major symptoms of malaria attack? & \\
Correct & 26,550 & 59.64 \\
Incorrect & 17,969 & 40.36 \\
If left untreated, which species of malaria is fatal? & \\
Correct & 25,079 & 56.33 \\
Incorrect & 19,440 & 43.67 \\
What should be done while malaria suffered? & \\
Correct & 39,218 & 88.09 \\
Incorrect & 5,301 & 11.91 \\
What measures could prevent malaria? & \\
Correct & 15,615 & 35.07 \\
Incorrect & 28,904 & 64.93 \\
\hline
\end{tabular}

Table 3 Characteristics of awareness of malaria in students in China

\begin{tabular}{|c|c|c|c|c|}
\hline \multirow[t]{2}{*}{ Characteristics } & \multicolumn{2}{|c|}{ Aware $(n=26,914)$} & \multicolumn{2}{|c|}{ Not-aware $(n=17,605)$} \\
\hline & $\begin{array}{l}\text { Excellent } \\
(\mathrm{n}=9,013)\end{array}$ & $\begin{array}{l}\text { Good } \\
(n=17,901)\end{array}$ & $\begin{array}{l}\text { Poor } \\
(n=15,743)\end{array}$ & $\begin{array}{l}\text { Very poor } \\
(n=1,862)\end{array}$ \\
\hline \multicolumn{5}{|c|}{ Age group, years } \\
\hline $6-9$ & 483 & 959 & 894 & 110 \\
\hline $10-14$ & 7,168 & 13,485 & 12,127 & 1,474 \\
\hline$\geq 15$ & 1,362 & 3,457 & 2,722 & 278 \\
\hline \multicolumn{5}{|l|}{ Sex } \\
\hline Male & 4,528 & 9,046 & 8,038 & 1,037 \\
\hline Female & 4,485 & 8,855 & 7,705 & 825 \\
\hline \multicolumn{5}{|l|}{ Education } \\
\hline $\begin{array}{l}\text { Elementary } \\
\text { school }\end{array}$ & 4,325 & 9,034 & 8,606 & 1,284 \\
\hline High school & 4,688 & 8,867 & 7,137 & 578 \\
\hline
\end{tabular}

parasitic diseases that seriously affected social-economic development. The estimated number of 1,829 malariaendemic counties (over $70 \%$ of total counties), and more than 30 million cases with about $1 \%$ fatality rate, existed at the establishment of the People's Republic of China in 1949. Endemic malaria was mainly caused by Plasmodium falciparum and Plasmodium vivax. Reported cases have significantly declined as endemic areas have proportionally reduced [6,7]. However, the epidemic situation of malaria in China is unstable, with long-term epidemics in the border areas of Yunnan province and vivax malaria reemergence in central China $[8,9]$. In order to further reduce the malaria burden as well as respond to the global goal of malaria eradication, China launched its NMEP in 2010, with a goal of malaria elimination nationwide by 2020 [1].

Public awareness of diseases, including malaria, plays an important role in disease control and prevention, a lack of reasonable knowledge of disease leads to low detection rate, the interruption of treatment and discrimination, etc. [5,10-12]. This study was a specific, population-based, cross-sectional survey, with the aim of assessing whether students at elementary and high school levels had knowledge of malaria. One of the limitations of this study was the selection bias without regard of financial situation, local education development and family history of malaria.

Some local studies about awareness of malaria have been carried out among the populations in China, but most were focused on adults, and only a few were conducted in schools [13-15]. As well as the general public, students at elementary and high schools had a lower awareness of malaria than the findings of the present study; meanwhile, significant differences of awareness of malaria between age groups, gender and 
education level respectively, were found in other studies, as well as the present survey [13-15].

The results of the present study demonstrated that the level of malaria awareness among students at elementary and high schools in China was generally low at the beginning of NMEP, and malaria-related student education should be further planned and strengthened in a localized and diversified manner. Moreover, not only basic knowledge but also information such as care-seeking practices should be included into future health education campaigns on malaria [16-18]. It is suggested that malaria elimination health education should cooperate with educational sectors to improve students' awareness of malaria. Future NMEP evaluation could use these results as a baseline for assessing the effectiveness of a programme.

\section{Competing interests}

The authors declared that they have no competing interests. The funders had no role in study design, data collection and analysis, decision to publish, or preparation of the manuscript.

\section{Authors' contributions}

$J H Y$ and ZGX conceived the study. RBW and ZGX participated in questionnaire design. RBW, QFZ and XYF participated in data collection. SSZ and XNZ provided the administrative coordination. JHY analysed the data and drafted the manuscript. ZGX revised the manuscript. All authors read and approved the final manuscript.

\section{Acknowledgements}

This work was supported by the Global Fund to Fight AIDS, Tuberculosis and Malaria (Grant No. CHN-S10-G13-M). The authors thank the workers in CDC/ institute of parasitic diseases and the teachers and students from 20 provinces/municipalities/autonomous regions of Zhejiang, Anhui, Gansu, Guangdong, Guangxi, Guizhou, Hunan, Hubei, Henan, Hainan, Jiangsu, Jiangxi, Liaoning, Shandong, Shannxi, Sichuan, Yunnan, Tibet, Chongqing, Shanghai, who participated in the study.

\section{Author details}

${ }^{1}$ National Institute of Parasitic Diseases, Chinese Center for Disease Control and Prevention, Shanghai 200025, People's Republic of China. ${ }^{2}$ WHO Collaborating Centre for Malaria, Schistosomiasis and Filariasis, Shanghai 200025, People's Republic of China. ${ }^{3}$ Key Laboratory of Parasite and Vector Biology, Ministry of Health, Shanghai 200025, People's Republic of China.

Received: 28 May 2013 Accepted: 8 July 2013

Published: 12 July 2013

\section{References}

1. Ministry of Health: [Action plan of China malaria elimination (2010-2020)] (in Chinese). China: P. R; 2010.

2. Bauch JA, Gu JJ, Msellem M, Martensson A, Ali AS, Gosling R, Baltzell KA: Perception of malaria risk in a setting of reduced malaria transmission: a qualitative study in Zanzibar. Malar J 2013, 12:75.

3. Andre Laas: The role of community education and involvement in malaria control. 2013. Available: http://www.malariaworld.org/forum/role-communityeducation-and-involvement-malaria-control.

4. The World Bank: What should schools do about malaria? 2013. Available: http://go.worldbank.org/ND7GG0K470.

5. Ayi I, Nonaka D, Adjovu JK, Hanafusa S, Jimba M, Bosompem KM, Mizoue T, Takeuchi T, Boakye DA, Kobayashi J: School-based participatory health education for malaria control in Ghana: engaging children as health messengers. Malar J 2010, 9:98.

6. Tang LH: [Chinese achievements in malaria control and research] (in Chinese). Zhongguo ji sheng chong xue yu ji sheng chong bing za zhi 1999, 17:257-257.
7. Tang LH: [Malaria in China: from control to elimination] (in Chinese). Guo ji yi xue ji sheng chong bing za zhi 2009, 36:258-285.

8. Zhou SS, Huang F, Wang JJ, Zhang SS, Su YP, Tang LH: Geographical, meteorological and vectorial factors related to malaria re-emergence in Huang-Huai River of central China. Malar J 2010, 9:337.

9. Sleigh $A C$, Liu XL, Jackson S, Li P, Shang LY: Resurgence of vivax malaria in Henan Province, China. Bull World Health Organ 1998, 76:265-270.

10. Becker GJ, McClenny TE, Kovacs ME, Raabe RD, Katzen BT: The importance of increasing public and physician awareness of peripheral arterial disease. J Vasc Interv Radiol 2002, 13:7-11.

11. Merakou K, Costopoulos C, Marcopoulou J, Kourea-Kremastinou J: Knowledge, attitudes and behaviour after 15 years of HIV/AIDS prevention in schools. Eur J Public Health 2002, 12:90-93.

12. Liu H, Li M, Jin M, Jing F, Wang $H$, Chen K: Public awareness of three major infectious diseases in rural Zhejiang province, China: a crosssectional study. BMC Infect Dis 2013, 13:192.

13. Dong Y, Wang XR, Zhou YB, Li CL, Wu XH, Wang ZY, Li CF, Guo XF, Liu H, Li L, LV SS, Fu KY, Li KH, Tang YQ: [Study on malaria knowledge in border population, Yunnan province](in Chinese). Chinese Journal of Schistosomiasis Control 2007, 19:59-63.

14. Li CF, Dong Y, Wang XR, Guo XF, LV SS: [Survey of malaria knowledge in primary school pupils and middle school students of 4 malaria endemic counties in Yunnan province](in Chinese). China Tropical Medicine 2005, 5:153

15. Sheng HF, Zheng X, Shi WQ, Xu JJ, Jiang WK, Wang DQ, Tang LH: [Factors affecting malaria outbreak in Congjiang county of Guizhou Province] (in Chinese). Zhongguo Ji Sheng Chong Xue Yu Ji Sheng Chong Bing Za Zhi 2007, 25:225-229.

16. Okello G, Ndegwa SN, Halliday KE, Hanson K, Brooker SJ, Jones C: Local perceptions of intermittent screening and treatment for malaria in school children on the south coast of Kenya. Malar J 2012, 11:185.

17. Das A, Das Gupta RK, Friedman J, Pradhan MM, Mohapatra CC, Sandhibigraha D: Community perceptions on malaria and care-seeking practices in endemic Indian settings: policy implications for the malaria control programme. Malar J 2013, 12:39.

18. Ghosh SK, Patil RR, Tiwari S, Dash AP: A community-based health education programme for bio-environmental control of malaria through folk theatre (Kalajatha) in rural India. Malar J 2006, 5:123.

doi:10.1186/1475-2875-12-237

Cite this article as: Yin et al: Students' awareness of malaria at the beginning of national malaria elimination programme in China. Malaria Journal 2013 12:237.

\section{Submit your next manuscript to BioMed Central and take full advantage of:}

- Convenient online submission

- Thorough peer review

- No space constraints or color figure charges

- Immediate publication on acceptance

- Inclusion in PubMed, CAS, Scopus and Google Scholar

- Research which is freely available for redistribution 